\title{
EU DRUID project: results of a questionnaire survey amongst participants of driver rehabilitation programmes in Europe
}

\author{
Simone Klipp
}

Received: 11 May 2009/Accepted: 12 November 2009/Published online: 27 November 2009

(C) European Conference of Transport Research Institutes (ECTRI) 2009

\begin{abstract}
Purpose This study was one part of the research activities of work package 5 "Rehabilitation" of the integrated EU DRUID project (6th Framework Programme). It aimed at gathering information about the cognitive-affective and behavioural processes that participants undergo while attending driver rehabilitation (DR) programmes. The primary objective was to analyse the outcomes of group interventions for alcohol offenders in order to assess any cognitive, motivational and behavioural modifications within individual participants and to identify the relevant variables which initiate and support this change process.

Methods The general methodological concept of the study was a prospective cohort design of participants of groupbased European driver rehabilitation programmes, carried out via a participant feedback questionnaire survey. In total $N=7.339$ DUI offenders in 9 European countries (Austria, Belgium, France, Germany, Great Britain, Hungary, Italy, Netherlands and Poland) participated in the survey.

Results The results indicate that DR participants feel such programmes provide strong support for their cognitive and behavioural change processes. The findings suggest that participants feel encouraged to establish new behavioural goals and the commitment to stick to them. At the same time, the participants' ratings emphasise the important role of the course leader in encouraging such changes.

Conclusions The findings of this explorative questionnaire survey are promising. Although it is impossible to draw any
\end{abstract}

S. Klipp $(\bowtie)$

Federal Highway Research Institute (BASt),

Bruederstr. 53,

51427 Bergisch Gladbach, Germany

e-mail: klipp@bast.de conclusions regarding long-term behavioural changes or effects on recidivism rates, participants of DR courses express positive feedback on completion of the programme. The positive outcomes of the study can motivate decisionmakers to launch DR measures and to regard them as an essential part of a comprehensive countermeasure system against DUI.

Keywords DUI · DWI · Driver rehabilitation .

Transtheoretical model · Programme evaluation · DRUID

\section{Introduction}

Driving under the influence of psychoactive substances remains one of the main causes of serious and fatal traffic injuries in the EU [15]. Driver rehabilitation (DR) is one possible countermeasure for drivers under influence of alcohol (DUI) and drivers under influence of illicit drugs (DUID). Thereby, the term driver rehabilitation comprises specific secondary interpersonal prevention measures that focus on attitudinal and behavioural changes of DUI/DUID offenders. It includes post-licensing measures for different driving-under-influence offender groups, but also covers measures for driving license applicants with an official record related to alcohol and/or illicit drug use. Drink driving offenders with a problematic drinking and driving pattern represent the main target group. Illicit drug driving offenders and individuals whose fitness to drive is in question due to an alcohol or illicit drug history, are further target groups. The primary aim of driver rehabilitation is to avoid new traffic offences under the influence of alcohol and/or illicit drugs, and/or to re-integrate the individual into the traffic system without imposing a risk on other traffic participants [6]. 
In the knowledge that sanctions (e.g. license revocation, fines and/or imprisonment) imposed on drivers who have committed serious offenses or accidents while being impaired due to alcohol and/or illicit drugs do not always result in behavioural change, the German-speaking countries took the first initiative to develop DR programmes in Europe in the late 1960s and early 1970s. Meanwhile, DR programmes for drink driving offenders have been implemented in many European Member States and the use of DR programmes for drug driving offenders is also increasing. Due to specific national situations and traditions, DR has not developed uniformly in Europe, but all DR programmes share the fundamental aim to modify the individual problem behaviour and to establish safetyoriented attitudes and behaviours in order to minimize reoffenses in the future. Various recidivism studies have already revealed the effectiveness of this approach $[1,3,4$, 9, 10, 19-21, 29, 36].

An extensive body of knowledge and expertise on DR now exists, but remains fragmented. Hence, DR was included as one specific major research topic of the integrated EU research project DRUID (Driving under the Influence of Drugs, Alcohol and Medicines; Project No. TREN-05-FP6TR-S07.61320-518404-DRUID) with the aim to both increase and systematize this knowledge. In a final step, Europe-wide standards for DUI/DUID intervention measures are to be elaborated.

This study was one part of the research activities of DRUID's work package 5 "Rehabilitation". The aim of the study was to gather information about the core elements of successful interventions for different drivers under the influence of psychoactive substances. As DR programmes aim at avoiding recidivism, but some participants do not profit sufficiently from these interventions and tend to reoffend despite participating in a DR measure, the international research team considered it necessary to analyze the cognitive-affective and behavioural processes participants undergo while attending a DR programme. The primary objective was thus to assess the outcomes of DR group interventions in order to gain insight into change processes, to appraise cognitive, motivational and behavioural modifications within individual participants and to identify the relevant variables which initiate and support the change process. Thereby, the study did not focus on evaluating single programmes, but targeted at gaining a comprehensive picture in general.

\subsection{General description of European DR group interventions}

The first group interventions offered in Europe followed the concept of "driver clinics" which were applied in North America and Canada in the 1960s and targeted recidivous traffic offenders in general. The first European interventions which have been offered target-specific for drink drivers since 1971 were so-called "group talks for repeated drivers under the influence of alcohol" [40]. Today, at least 77 DR providers in 12 European countries offer a pool of 87 different programmes [24]. Besides some variations depending on different national legal frame conditions (see Section 1.2), the programmes share some common features [23]. Although the group sizes vary between 6 up to 20 persons and the programme durations range between 10 to $40 \mathrm{~h}$, the intervention approach is commonly a psychological one with educative elements. Hence, most of the programmes are led by specifically trained course leaders, mostly psychologists. As the programme concepts are target-group specific, alcohol offenders are not mixed with drug or general traffic offenders in the majority of cases [24]. Addicted offenders are usually excluded from participation in such group programmes. Typically, the programmes last over several weeks with the same course leader and the same course participants which provides a basis for effects of group dynamic processes. The typical course schedule runs as follows. The first session focuses on the establishment of an open, trustworthy group climate and the willingness to work on the problem behaviour. In addition, the frame conditions of participation, e.g. confidentiality and sobriety during the course sessions, are clarified and often fixed in a contract which is signed by each participant. In this starting session, it is very important to provide the participants with the opportunity to speak out their frustration, anger, shame and reluctance to participate, but also to clarify the course leader's role as moderator and facilitator of group discussions as participants are often worried to get instructions and lessons from a teacher including examinations like in school or driving school. The participants introduce themselves directly or by means of partner interviews in order to support group cohesion. When the initial phase is finished, first approaches to content-related topics are made, e.g. the collection of relevant themes that should be discussed during the course and the collection of the participants' ideas about the main conditions or factors which led to their drink driving offence. Based on these suggestions, common goals can be identified and an agreement on further steps that need to be taken can be defined easily. Participants often have questions about their individual situation or next steps to license reinstatement. This in turn gives the opportunity to include the experiences of the other course participants. At the end of the first session, a short feedback of each participant can provide useful information about the group climate reached so far. In the following sessions - the exact number varies according to national regulations - the main issues dealt with are directly or indirectly related to the DUI offence. These include self-estimation of subjective 
alcohol-related impairments in contrast to objective facts, prior and actual drinking habits and interferences with driving, prior drink driving habits, motives for alcohol consumption, influence of friends, colleagues, peers on the alcohol consumption, basic physiological information on alcohol, importance of car use in private and professional life, negative consequences of the loss of the driving license, detailed analyses of the DUI offence that led to course participation, establishment and reinforcement of change motivation including individual homework tasks between the sessions, e.g. avoiding alcohol consumption in bars or clubs at the weekend and keeping a diary about consumed alcohol. In the final course phase, the future behaviour regarding drinking and driving is the main focus. Thereby, potential strategies, plans and intentions to avoid re-offenses in traffic are collected and discussed, taking the individual constellation of the problem behaviour into account. Realistic solutions are discussed and worked out within the group. In the final phase of the programme, it is important to reinforce the participants to realize their personal goals regarding the avoidance of subsequent offenses in order to not only get the license back, but also to keep it in future.

\subsection{International differences of European DR group interventions}

Basic differences between the DR programmes carried out in European countries are more related to structural issues of programme implementation and modes of participation than to individual differences between each of the programmes [7]. Although in most countries participation is legally regulated (e.g. Austria, Belgium, France, Germany, Hungary, Netherlands and United Kingdom), there are still countries that did not yet establish legal regulations concerning the participation in DR measures (e.g. Italy and Poland). In most cases, legal regulations specify the modes of participation and define the conditions and formal criteria for mandatory participation. In Austria and the Netherlands for instance, all offenders above a specified BAC (1.2\% in Austria and 1.3\% in the Netherlands) have to participate. In most cases participation is ordered by the licensing authorities or otherwise by the court or the public prosecutor. But even though a country may have yet implemented regulations for programme participation, it is not necessarily the case that in these countries the participation is mandatory as regulations may also concern voluntary participation (e.g. specification of target groups or exclusion criteria, legal consequences of voluntary participation). Half of the programmes offered in Europe are voluntary ones [7], whereby the mode of voluntary participation must be seen with caution as offenders are often "forced to participate on a voluntary base" in order to avoid further negative sanctions or measures. In Belgium for example, a judge can propose a DR course as an alternative within the scope of probation. It is up to the offender to accept this rehabilitation offer or not. In case it is not accepted by the offender, the original sentence is carried out though. Although the decision to participate in a DR course is strictly speaking voluntary, the offenders are quite forced to participate, as the alternative would be either to be referred to police court, or being subject to execution of the full sentence [5]. In Germany, as another example, offenders can be referred to a course for the restoration of the fitness to drive if this is recommended within a medical psychological assessment. The licensing authority needs to agree to this decision. The fitness to drive is regarded as restored after successful completion of the course. Hence, the successful participation has legal consequences: if the offender submits the certificate of attendance, the driving licence is immediately reissued without any new assessment or additional obligations. Although the participants of these courses often feel that participation is mandatory, while it is actually voluntary. The alternative to course participation would be passing a new driver assessment, as often as the assessment succeeds in a positive result which is by far the more difficult alternative. Hence, for the evaluation of the mode of participation (voluntary vs. mandatory), the consequences of participation (or nonparticipation) always have to be taken into account. In the majority of cases, successful participation in a DR programme is a necessary condition for license reinstatement or the ongoing validity of the license. Successful course completion may also lead to other positive consequences, e.g. reduction of the suspension period, avoidance of further prosecution or replacement of sanctions. Table 1 provides an overview of structural features of the programmes in different European countries.

\section{Methods}

The general methodological concept of the study was a prospective cohort design of participants of European DR group programmes, carried out via a DR participant feedback questionnaire survey (see Section 2.1). In order to gain the most comprehensive data set, as many participants as possible from different European countries were included in the study (see Section 2.2).

\subsection{Survey instrument and procedure}

The survey instrument was based on two theoretical concepts: the Transtheoretical Model of Change (TTM) [32-34] and the Diamond of Change which was developed by the DRUID research group. 
Table 1 Structural features of the programmes in different European countries

\begin{tabular}{|c|c|c|c|c|c|c|}
\hline & & $\begin{array}{l}\text { Legally } \\
\text { regulated } \\
\text { participation }\end{array}$ & $\begin{array}{l}\text { Instance } \\
\text { imposing/ } \\
\text { proposing } \\
\text { participation }\end{array}$ & $\begin{array}{l}\text { Criteria for } \\
\text { programme } \\
\text { assignment }\end{array}$ & $\begin{array}{l}\text { Mode of } \\
\text { participation }\end{array}$ & $\begin{array}{l}\text { Consequences of } \\
\text { participation }\end{array}$ \\
\hline \multicolumn{2}{|l|}{ Austria } & yes & $\begin{array}{l}\text { Licensing } \\
\text { authority }\end{array}$ & $\mathrm{BAC}>1.2 \% 0$ & mandatory & License reinstatement \\
\hline \multicolumn{2}{|l|}{ Belgium } & yes & $\begin{array}{l}\text { Public } \\
\text { prosecutor, } \\
\text { court }\end{array}$ & $\begin{array}{l}\text { No license } \\
\text { withdrawal } \\
(\sim \text { BAC }<1.6 \%) \\
\& \text { offender }<26 \\
\text { years }\end{array}$ & voluntary & $\begin{array}{l}\text { Reduction of suspension } \\
\text { period \& other } \\
\text { sanctions, avoidance of } \\
\text { further prosecution }\end{array}$ \\
\hline \multicolumn{2}{|l|}{ France } & yes & $\begin{array}{l}\text { Public } \\
\text { prosecutor, } \\
\text { court }\end{array}$ & $\mathrm{BAC}>0.8 \%$ & $\begin{array}{l}\text { voluntary \& } \\
\text { mandatory }\end{array}$ & $\begin{array}{l}\text { Reduction of suspension } \\
\text { period, avoidance of } \\
\text { further prosecution or } \\
\text { other sanctions }\end{array}$ \\
\hline \multirow[t]{3}{*}{ Germany } & $\begin{array}{l}\text { Type I "Special advanced driver } \\
\text { improvement courses" }\end{array}$ & yes & $\begin{array}{l}\text { Licensing } \\
\text { authority }\end{array}$ & $\begin{array}{l}\text { Novice drivers } \\
\text { with DUI } \\
\text { offense }\end{array}$ & mandatory & $\begin{array}{l}\text { Ongoing validity } \\
\text { of the license or } \\
\text { license reinstatement }\end{array}$ \\
\hline & $\begin{array}{l}\text { Type II "Courses for the } \\
\text { restoration of the fitness to } \\
\text { drive" }\end{array}$ & yes & $\begin{array}{l}\text { Licensing } \\
\text { authority }\end{array}$ & $\begin{array}{l}\text { Prior driver } \\
\text { assessment }\end{array}$ & voluntary & License reinstatement \\
\hline & $\begin{array}{l}\text { Type III Courses to apply for } \\
\text { reduction of the suspension } \\
\text { period or to prepare for the } \\
\text { medical psychological } \\
\text { assessment }\end{array}$ & no & - & - & voluntary & $\begin{array}{l}\text { Reduction of suspension } \\
\text { period possible, } \\
\text { increased chances to } \\
\text { pass subsequent } \\
\text { assessment }\end{array}$ \\
\hline \multicolumn{2}{|c|}{ Great Britain } & yes & Court & $\begin{array}{l}\text { Suspension } \\
\text { period } \geq 12 \\
\text { months \& } \\
\text { offender } \geq 17 \\
\text { years }\end{array}$ & voluntary & $\begin{array}{l}\text { Reduction of suspension } \\
\text { period }\end{array}$ \\
\hline \multicolumn{2}{|l|}{ Hungary } & yes & Court & $\begin{array}{l}\text { Prior driver } \\
\text { assessment }\end{array}$ & mandatory & License reinstatement \\
\hline \multicolumn{2}{|l|}{ Italy } & no & $\begin{array}{l}\text { Assessment } \\
\text { centre }\end{array}$ & $\begin{array}{l}\text { Prior driver } \\
\text { assessment }\end{array}$ & mandatory & License reinstatement \\
\hline \multicolumn{2}{|c|}{ Netherlands } & yes & $\begin{array}{l}\text { Licensing } \\
\text { authority }\end{array}$ & $\begin{array}{l}\text { BAC }>1.3 \%, \\
\text { BAC }>0.8 \% 0 \\
\text { for novices } \\
\text { drivers \& } \\
\text { recidivists }\end{array}$ & mandatory & $\begin{array}{l}\text { Ongoing validity } \\
\text { of the licence }\end{array}$ \\
\hline \multicolumn{2}{|l|}{ Poland } & no & Prison & $\mathrm{BAC}>0.5 \%$ & voluntary & $\begin{array}{l}\text { Reduction of the } \\
\text { prison term possible }\end{array}$ \\
\hline
\end{tabular}

The TTM [32-34] provides a detailed description of the cognitive, affective and behavioural processes of an intentional change in behaviour. Since its development, it has been validated in the fields of diagnostic and treatment of alcohol problems [12, 14, 27]. Moreover, its application has become widespread in the diagnosis of DUI offenders $[16,25,38,39]$ and the evaluation of DUI rehabilitation $[26,31,35,37]$.

The TTM assumes that an intentional change of a problematic behaviour proceeds via five stages (Precontemplation, Contemplation, Preparation, Action and Maintenance). Besides, and of even more value for this study's concept, the TTM postulates ten processes of change that individuals make use of in progressing from one stage to the next [13]. These processes were theoretically derived from different types of therapy and encompass the integrative structure of the TTM, thereby accounting for the word "transtheoretical" in the model's name. The use of these overt or covert activities determines the movement from stage to stage [13, 32]. Five cognitive-affective processes (experiential processes) and five behavioural processes can be distinguished. The cognitive-affective processes (Consciousness raising, Dramatic relief, Environmental reevaluation, Self-re-evaluation \& Social liberation) play an important role in the earlier stages when an intention to change is created (motivation). The behavioural processes 
(Self-liberation, Stimulus control, Counter conditioning, Helping relationships \& Reinforcement management) are more important in the later stages, representing the implementation of an intention (volition) and translation into concrete behaviour (action).

The second theoretical concept, the Diamond of Change [8], describes certain key elements that are supposed to initiate and to contribute to change processes in DR group interventions. These key elements basically originated from outcomes of evaluation studies in psychotherapy and addiction research as well as from personal long-standing experience as leaders of DUI/DUID group courses. Findings from a prior EU ANDREA Project (Analysis of Driver Rehabilitation Programmes) [2] also provided relevant input.

The following five key elements, or contributing factors, are considered to be important and to initiate the motivational and behavioural change in the participants of DR courses: I = Individual; this key element is defined as the participant's self-acceptance and self-efficacy; PTR $=$ Participant-trainer relations; meaning the interpersonal relationship between the DR participant and trainer; PPR = Participant-participant relations; this element concerns the interpersonal relationship between the course participants; $\mathrm{C}=$ Contents; defined as the modules of the DR-measure; $\mathrm{M}=$ Methods; this element takes into account the ways and means in which the contents are presented and how the course is conducted. As all five factors are seen to be key elements of equal importance interacting with each other and intertwined in a complex way, the structure of a diamond was chosen to illustrate this and the name 'Diamond of Change' was created (see Fig. 1).

As a consequence, the feedback questionnaires consisted of items with statements mirroring the different change processes. The items were developed on the basis of German and English versions of the TTM-related questionnaires SOCRATES [30], RTCQ [18], URICA [28] and POCA-G [11]. Within each item one of the corners of the Diamond of Change was always presented in order to identify the factor which contributed to the specific processes ("contributing factors"). Thus the items consisted of two elements: the contributing factor (mainly at the beginning of the sentence) and a statement representing the process that may have been undergone, e.g. "Through the way the course was conducted ( method) I see some of my troubles in a different way ( self-re-evaluation)". Participants were asked to mark their agreement with the items on a Likert-type scale with four possibilities (agree completely, agree mostly, disagree mostly, and disagree completely). Besides the concept-related items, an overall evaluation of the course was requested (very good, good, poor, very poor). In addition, a series of questions on sociodemographics and offense-related variables such as blood alcohol concentration (BAC), prior DUI convictions and prior DR course participation were included. The survey instrument was improved within two test runs and the final version was translated into several languages [German (German and Austrian), English (British), French (French and Belgian), Dutch (Dutch and Flemish), Hungarian and Polish]. As the focus of the study was not on evaluating single programmes, but also in order to fulfil the ethical requirements regarding anonymization and data protection imposed by the EU Commission for the DRUID research, the specific programmes were not coded on the questionnaires.

The data collection lasted from August 2007 until January 2008. The questionnaires were distributed to the participants after they had received their certificates of attendance at the end of the final group session. For data protection reasons, and also to avoid answers biased by social desirability, the participants sealed the questionnaires in envelopes after filling them out. Subsequently, the course leader collected the envelopes and the providers sent them to the research team.

\subsection{Sample description}

In total $N=7.339$ DUI offenders in 9 European countries (Austria $n=1,646$, Belgium $n=103$, France $n=686$, Germany $n=2,351$, Great Britain $n=1,022$, Hungary $n=$ 657, Italy $n=140$, Netherlands $n=501$ and Poland $n=233$ ) participated in the questionnaire survey. The mean age of the DUI sample was 34 years old $(\mathrm{SD}=12.6)$ with $10.7 \%$ being female. The average BAC of the sample was $1.43 \%$ $(\mathrm{SD}=0.58)$. Nearly $60 \%$ of the survey participants lived in small towns and only one fourth completed full secondary school education or higher education. Almost one fourth was detected due to an accident and approximately the same amount were recidivists. Nearly $12 \%$ already participated in a DR programme prior to the current one. Detailed results regarding demographics and offenserelated variables for the whole European sample are presented in Table 2; selected variables are displayed on a country level in Table 3 .

\subsection{Data analysis}

Data processing was carried out by the Austrian Road Safety Board (KfV). Data were analyzed for the total European sample. Besides the country variables, all included socio-demographic and offense-related data served as independent variables in the subsequent analyses, whereby the variable "educational background" was dichotomized to $0=$ no completion of full secondary education and $1=$ at least completion of full secondary education (higher education than compulsory and secondary school attendance). 
Fig. 1 The diamond of change

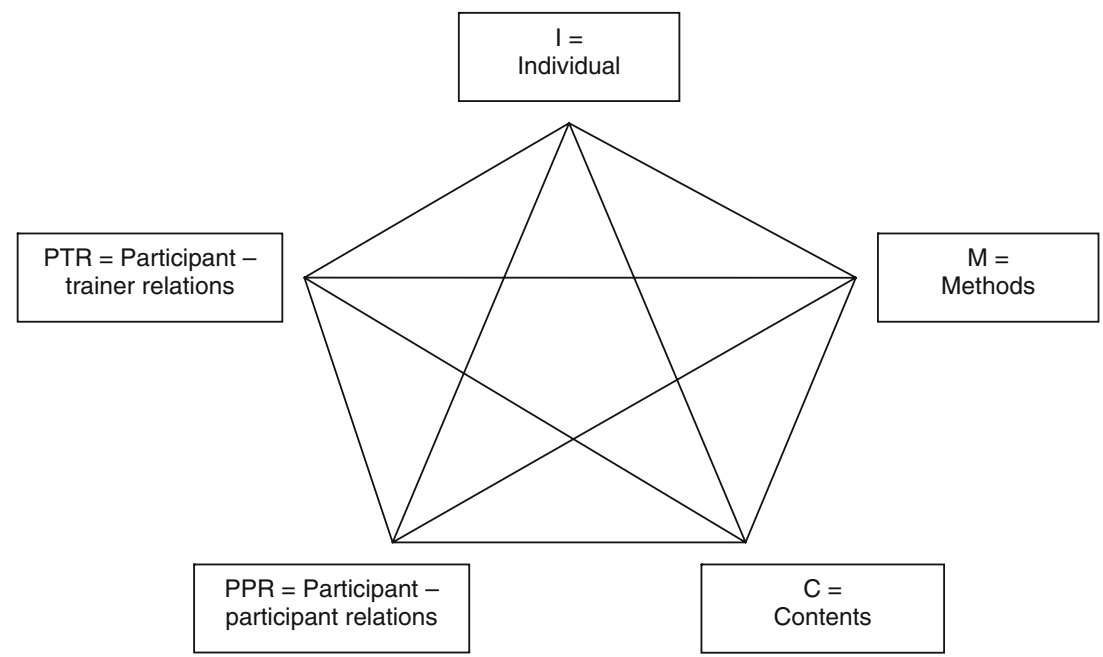

Besides conventional descriptive statistical measures as absolute frequencies and percentages for categorical variables and mean \pm standard deviation for continuous variables, statistical group comparisons were performed by $t$-tests for independent samples when comparing only two groups. In the case of more than two groups (e.g. when comparing different country means) differences were tested by using analysis of variance models (ANOVA). If significant differences between groups were detected, post hoc Scheffétests were performed as this conservative test procedure is robust to violations of its statistical assumptions and allows comparisons a posteriori in the case of unequal sample sizes.

Table 2 Demographic variables - total European sample $(N=7,339)$

\begin{tabular}{lc}
\hline Variables & Results (\% of total sample) \\
\hline Cohabitating $(N=6,335)$ & $3,036(41.4 \%)$ \\
no & $3,299(45.0 \%)$ \\
yes & \\
Size of residence $(N=6,741)$ & $4,274(58.2 \%)$ \\
$<100.000$ & $1,368(18.6 \%)$ \\
$100.000-500.000$ & $1,099(15.0 \%)$ \\
$>500.000$ & \\
Education $(N=6,013)$ & $140(1.9 \%)$ \\
No compulsory school & $1,312(17.9 \%)$ \\
Compulsory school & $2,612(35.6 \%)$ \\
Secondary school & $804(11.0 \%)$ \\
A-level & $395(5.4 \%)$ \\
Vocational school & $263(3.6 \%)$ \\
College & $487(6.6 \%)$ \\
Academic & \\
Prior participation in DR course $(N=6,684)$ & $5,828(79.4 \%)$ \\
no & $856(11.7 \%)$ \\
yes &
\end{tabular}

A $T$-test for dependent samples was used for pair-wise testing in order to analyze within-group variations. Interrelations of continuous variables were analyzed using Pearson's correlation coefficient and those of rank-ordered variables using Spearman's rank correlation coefficient.

All statistical analyses were performed using SPSS 17.0. Due to the large sample size and to a possible inflation of the error type I-because of multiple testing-only $p$-values $<.01$ were considered strong indicators. Significant $p$-values were supplemented by the respective effect sizes to support correct interpretations of the results.

\section{Results}

\subsection{Overall course evaluation}

All European courses received very positive overall feedback. The overall evaluations of the total sample show that almost $95 \%$ of the course attendees rated the course as good or even better $(N=7,108 ; M=1.52 \pm 0.56)$. Only a small number of participants $(2.2 \%)$ gave negative feedback by evaluating the course as bad or worse. The country comparison revealed highly significant differences between all countries in the overall evaluations $(p<.001$; Table 4), whereby post-hoc testing revealed the superiority of British courses regarding this aspect (Table 5). Regarding the influence of age and BAC on the overall course evaluation, significant correlations appear, but only with small effect sizes (age: $r=-.17 ; p<.001$; BAC: $r=-.03$; $p=.008)$. Women generally tend to evaluate the course better (female: $M=1.41 \pm 0.53$; male: $M=1.54 \pm 0.56$; $d=$ $0.22 ; p<.001)$, but the gender effect is also rather small. Neither being a recidivist nor the educational background, dichotomized to having completed full secondary education (or higher) vs. non-completion, had a significant 
Table 3 Selected sample variables - total sample and country characteristics

\begin{tabular}{|c|c|c|c|c|c|}
\hline & $\begin{array}{l}\text { Age }(\text { Mean in } \\
\text { years } \pm \text { SD) }\end{array}$ & Male $N(\%)$ & $\begin{array}{l}\text { BAC value at offense } \\
\text { (Mean in } \% \pm \pm \text { SD) }\end{array}$ & $\begin{array}{l}\text { Accident at DUI } \\
\text { offense } N(\%)\end{array}$ & $\begin{array}{l}\text { Recidivists } \\
N(\%)\end{array}$ \\
\hline Europe total $(N=7,339)$ & $34.1 \pm 12.6$ & $6,356(86.6 \%)$ & $1.43 \pm 0.58$ & $1,751(23.9 \%)$ & $1,706(23.2 \%)$ \\
\hline Austria $(N=1,646)$ & $36.1 \pm 13.0$ & $1,420(86.3 \%)$ & $1.47 \pm 0.49$ & $380(23.1 \%)$ & $515(31.3 \%)$ \\
\hline Belgium $(N=103)$ & $37.6 \pm 12.8$ & $93(90.3 \%)$ & $1.55 \pm 0.63$ & $36(35.0 \%)$ & $32(31.1 \%)$ \\
\hline France $(N=686)$ & $37.5 \pm 12.4$ & $601(87.6 \%)$ & $1.36 \pm 0.65$ & $69(10.1 \%)$ & $85(12.4 \%)$ \\
\hline Germany $(N=2,351)$ & $29.8 \pm 11.5$ & $2,031(86.4 \%)$ & $1.38 \pm 0.58$ & $687(29.2 \%)$ & $438(18.6 \%)$ \\
\hline Great Britain $(N=1,022)$ & $34.7 \pm 13.2$ & $817(79.9 \%)$ & $1.36 \pm 0.46$ & $211(20.6 \%)$ & $130(12.7 \%)$ \\
\hline Hungary $(N=657)$ & $37.7 \pm 10.8$ & $622(94.7 \%)$ & $1.76 \pm 0.71$ & $228(34.7 \%)$ & $151(23.0 \%)$ \\
\hline Italy $(N=140)$ & $29.8 \pm 9.6$ & $130(92.9 \%)$ & $1.30 \pm 0.48$ & $22(15.7 \%)$ & $31(22.1 \%)$ \\
\hline Netherlands $(N=501)$ & $36.3 \pm 12.6$ & $415(82.8 \%)$ & $1.29 \pm 0.42$ & $70(14.0 \%)$ & $185(36.9 \%)$ \\
\hline Poland $(N=233)$ & $37.2 \pm 10.7$ & $227(97.4 \%)$ & $1.41 \pm 0.86$ & $48(20.6 \%)$ & $139(59.7 \%)$ \\
\hline
\end{tabular}

influence on the overall course evaluation (recidivism: $p=.828$; education: $p=.221$ ). All results of the analyses of socio-demographic and offense-related variables as independent variables are displayed in Table 6.

\subsection{TTM processes}

The results for the overall means on each scale of the TTM based on the answering format in the feedback questionnaire $(1=$ agree completely, $2=$ agree mostly, $3=$ disagree mostly, $4=$ disagree completely) reveal that course participants generally show high agreement on all process scales (see descriptive statistics in Table 4) with the European means ranging from $M=1.39( \pm 0.56)$ to $M=$ $1.92( \pm 0.97)$. Thereby the participants show highest agreement with the items representing 'self-liberation', meaning they found the course supportive for their choice and commitment to change their behaviour. On the contrary, participants agree less on scales representing environmental re-evaluation and dramatic relief. Hence, they experienced the course to be less supportive for altering the perception and assessment of how the problem behaviour affects their physical and social environment and lacked emotional involvement somehow. When comparing the overall sum score means for all cognitive affective processes to the overall sum score means for all behavioural processes for the total European sample, it becomes obvious that the participants agree significantly higher ( $t=$ 43.02; $\mathrm{df}=7,231 ; p<.001)$ on scales for the behavioural processes $(M=1.50 \pm 0.50)$ than on scales for the cognitive affective processes $(M=1.69 \pm 0.49)$. Results of the multiple comparison analyses reveal significant differences $(p<.001)$ between the countries on almost all process scales. Only on the scale for the items representing social liberation was the highest $p$-value reached $p=.002$, indicating that regarding the support of the development of alternative behaviour, measured by the participants opinion, the programmes differ little in the respective countries. Again, on most of the scales the participants of the British courses, but also participants of the Polish courses, show highest agreement and, hence, felt strongly supported. All multiple comparison results of post-hoc testing are displayed in Table 5 . Highly significant correlations exist of all process scales' agreement scores with the age of the participants (except for the dramatic relief scale), and also with the BAC (except for the social liberation and helping relationships scales), but the effect sizes are too small to indicate a relevant interrelation of these independent variables and the agreement score (age: $r_{\max }=-0.16 ; p<.001 ;$ BAC: $\left.r_{\max }=-0.07 ; p<.001\right)$. Women tend to agree significantly higher with the items representing consciousness raising $(d=0.19 ; p<.001)$, self-re-evaluation $(d=0.15 ; p<.001)$, social liberation $(d=0.13 ; p=.001)$, self-liberation $(d=$ $0.19 ; p<.001)$ and counter conditioning $(d=0.13 ; p=.001)$. More highly educated participants agree less on the TTM scales for environmental re-evaluation $(d=-.20 ; p<.001)$, social liberation $(d=-.16 ; p=.002)$, stimulus control $(d=-.20 ; p=.001)$, counter conditioning $(d=-.15 ; p=.004)$ and reinforcement management $(d=-0.23 ; p<.001)$ than lower educated participants. Recidivists tend to agree more with statements for consciousness raising $(d=0.08$; $p=.003)$, environmental re-evaluation $(d=0.09 ; p=.001)$, self-re-evaluation $(d=0.12 ; p<.001)$, counter conditioning $(d=0.09 ; p=.001)$ and reinforcement management $(d=0.08$; $p=.005$ ). All results of the analyses of socio-demographic and offense-related variables as independent variables are displayed in Table 6.

\subsection{Diamond of change}

All five corners of the diamond that were assumed by the research team to be factors contributing to change processes 


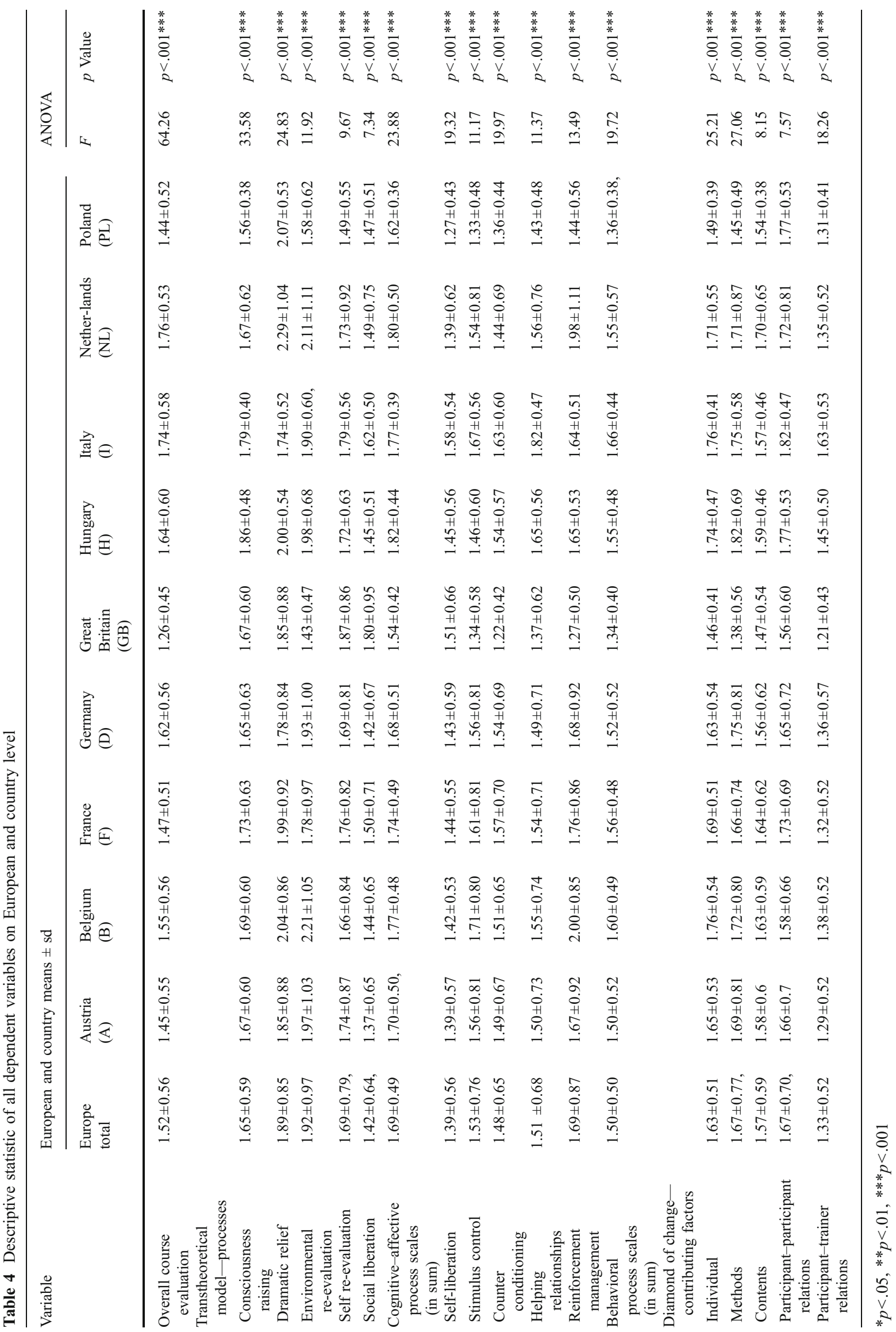


are affirmed by the participants' ratings. Thereby, the participant-trainer relations is judged to be the most supportive factor by the total European sample $(M=1.33 \pm$ $0.52)$. The methods $(M=1.67 \pm 0.77)$ and the other participants $(M=1.67 \pm 0.70)$ are considered to be of least importance, but still gain relatively high scores for agreement (Table 4). The country comparisons reveal significant differences between the countries regarding the participants' ratings of the importance of the different contributing factors $(p<.001)$, whereby the multiple comparison analyses reveal least differences between the participants in the countries regarding the value of the course contents and the participant-participant relations (Table 5). Again it becomes apparent that the British and Polish courses achieve the highest agreement scores. Age is negatively correlated with the agreement scores for all contributing factors, indicating that younger persons agree more than older persons $(p<.001)$. The effect of age is largest on the items representing the individual itself as a contributing force $(r=-.21 ; p<.001)$. Although significant correlations with the BAC appear for the scales representing the individual $(r=-.08 ; p<.001)$, the contents $(r=-.06$; $p<.001)$ and the participant-trainer relations $(r=-.04$; $p=.003)$ as contributing factors, an interrelation of the BAC and the ratings cannot be assumed due to the low effect sizes. Highly significant differences also result for the effect of gender $\left(d_{\max }=0.19 ; p<.001\right)$, education $\left(d_{\max }=-0.24 ; p<.001\right)$ on all contributing factors. Recidivism only appears to have a significant effect on the ratings representing the individual $(d=0.12 ; p<.001)$ and the methods $(d=0.10 ; p<.001)$. All results of the analyses of socio-demographic and offense-related variables as independent variables are displayed in Table 6 .

\section{Discussion}

The results of this explorative questionnaire survey indicate that the participants of DR programmes felt that the programmes strongly supported their cognitive and behavioural processes of change. It seems that participation in the course helps to increase problem awareness and to change the problem-related perception of the environment and the self. Above all, the participants affirm that they felt encouraged to establish new behavioural goals and the commitment to stick to them. They became aware of alternative behaviour and learned to substitute it for the problem behaviour. The comparison of the agreement scores on the scales for the behavioural processes and the scales for the cognitiveaffective processes suggest that the DR programmes are strongly behaviour-oriented. Thereby, the ratings point towards the important role of the course leader in promoting behavioural changes.

The sub-analysis regarding the independent variables hint at significant influences of different variables on the ratings, but a real influence is actually questionable when considering the small effect sizes. Hence, it is more likely that these differences basically result from the large sample size $(N=7.339)$. Common sense dictates that, given a sufficiently large sample size, it is always possible to show two means differing significantly or correlations gaining a highly significant $p$-value, particularly if effect sizes are small. Thus, the practical value of these findings is doubtful.

Admittedly, some other methodological limitations may reduce the explanatory power of the study as a visual inspection of the data already reveals an obvious tendency towards positive answers. On the one hand, this may be due to a general ceiling effect which occurs when the items are too easy to answer. This would indicate a weakness in the sensitivity of the questionnaire. This lack-of-sensitivity argument is even confirmed by the fact that some scales are highly significantly correlated with medium to large effect sizes (between $r=.24$ and $r=.46$ ). On the other hand, the positive response tendency can also accrue from the survey procedure as participants filled out the questionnaire after having received the certificate of attendance. Although this procedure was intentionally chosen to make the participants' answers independent from successful completion of the course and to avoid socially desirable answers, the receipt of the certificate may have functioned as a 'steepening incentive', increasing the tendency to give positive answers. This tendency may be highest among the British and Polish participants, making the courses in these countries appear superior. The multiple country comparisons reveal significant differences which probably support this assumption. It could well be due to the high quality of the courses in these countries, but the findings may also be subject to some kind of selfselection bias. The programmes evaluated in this study in Great Britain and Poland are solely attended on a voluntary basis in contrast to the programmes in Austria or the Netherlands, for example, where participation is always mandatory for DUI offenders above a certain BAC threshold (see overview in Table 1). This assumption is supported by specific analyses of the data of the German sample [22]. Here, the variable 'mandatory versus voluntary participation' was controlled in so far as some programme types are solely mandatory and some are solely voluntary. The programme type was included in the further analyses as an independent variable and the results revealed significant differences with even large effect sizes in the assumed direction: the voluntary programmes were considerably better assessed than the mandatory 


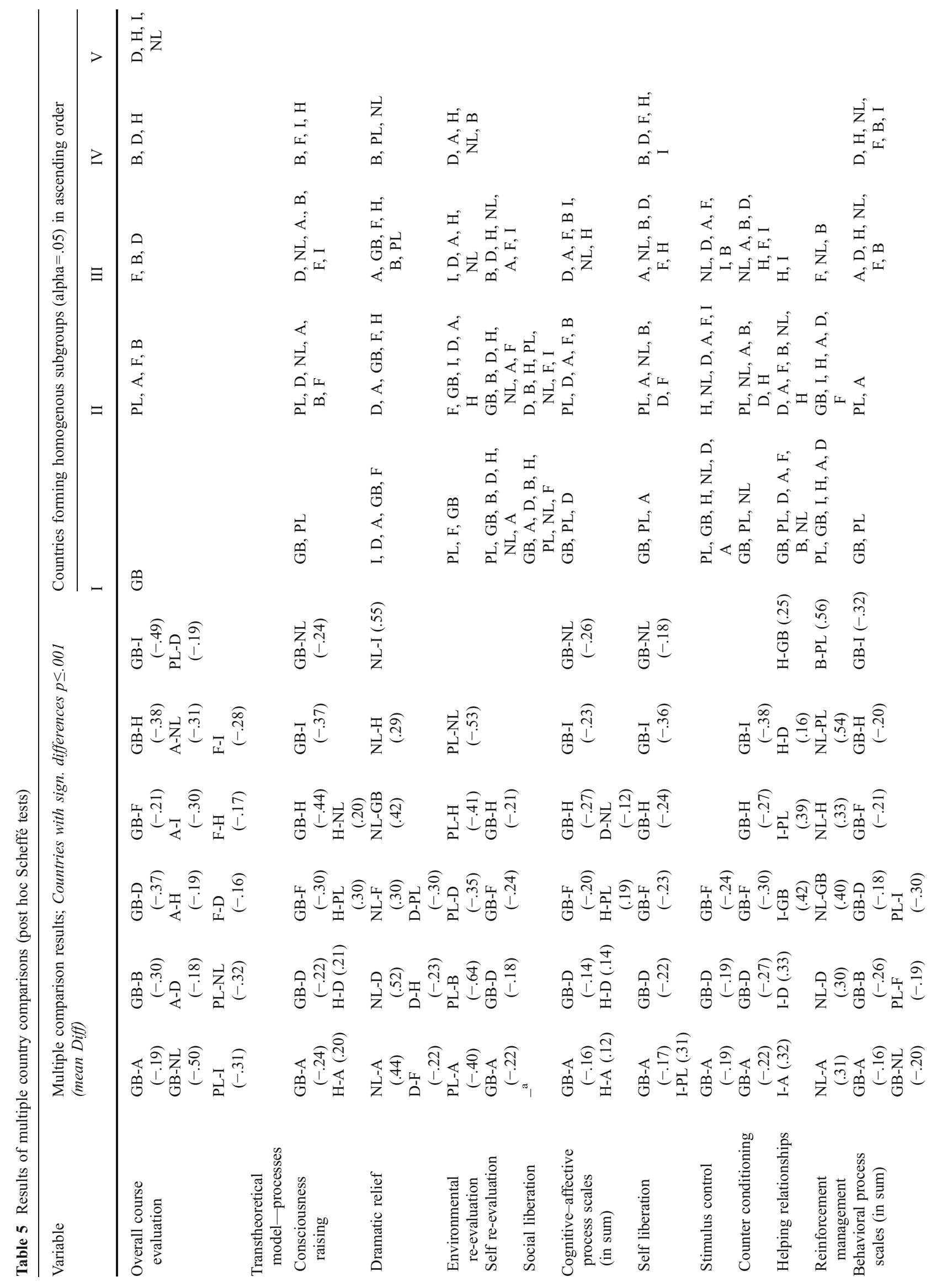




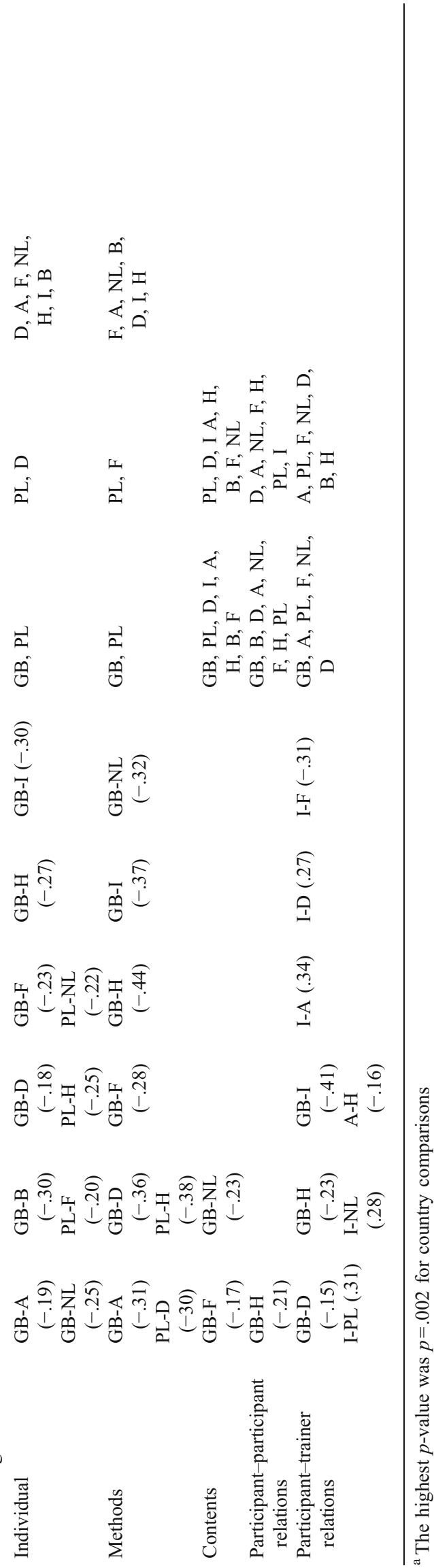

ones. These results are not surprising, as voluntary participation means that the individuals who decide to attend a course are likely to be highly motivated and expect it to be beneficial. These advantages are enhanced by offering obvious reward stimuli which enhance extrinsic motivation. In this study, British offenders who successfully completed the course gained a reduction in their suspension period and successful Polish offenders were very likely to have their prison term reduced. Hence, the 'steepening incentive' effect may even increase for those participants. In any case, those who decide to participate voluntarily are intrinsically motivated and may also expect advantages for themselves and their future behaviour. Thus, when they are subsequently asked for their opinion on what the programme achieved, they are likely to evaluate the programme positively in order to avoid negative feelings along the lines of the theory of cognitive dissonance [17]. Nevertheless, the good to very good overall evaluations of all European courses show that even those DUI offenders who participate on a mandatory basis, and who are often reluctant at the beginning of a programme, are convinced of the programme's supportive function and express high acceptance on completion of the course.

All in all, the findings of this explorative questionnaire survey are promising in terms of acceptance. Although it is impossible to draw any conclusions regarding any long-term behavioural changes or effects on recidivism rates, participants of DR courses express positive feedback after succeeding the programme. The fact that this large sample, recruited from various nations, felt that these courses strongly supported the individual change processes that are targeted by $D R$ measures may at least trigger the implementation of DR programmes. Furthermore, and considering the fact that European group intervention programmes for DUI offenders show an average recidivism reduction rate of $45.5 \%$ [23], these results should motivate decision-makers in those countries which did not yet establish DR programmes to launch DR measures and to regard them as an essential part of a comprehensive countermeasure system.

Acknowledgements The author would like to thank the following colleagues of the DRUID research team who contributed to this study: Birgit Bukasa, Sofie Boets, Eveline Braun, Uta Meesmann, Elisabeth Panosch and Ulrike Wenninger, for all their work and pleasant cooperation. Thanks are also due to Elisabeth PonocnySeliger for her assistance with data management and to all participating providers in Europe for their highly appreciated efforts to contribute to this research. I further acknowledge the funding of the EU DRUID project by the European Commission as the realization of this study would not have been possible without its support. 


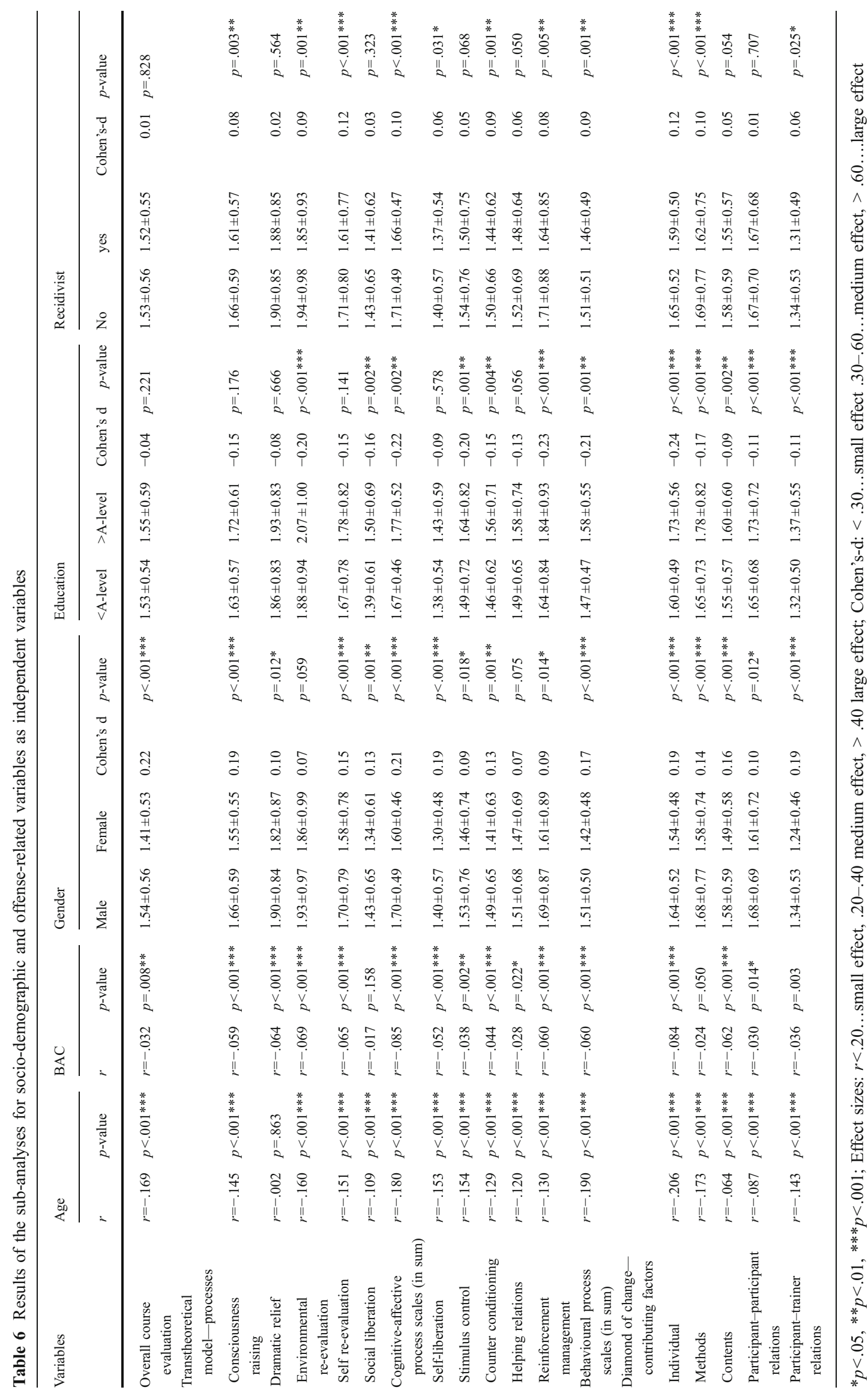




\section{References}

1. Bächli-Biétry J (2006) Lernprogramme als neue Interventionsform in der Strafjustiz, Evaluationsbericht des Modellversuchs [Educational programmes as new intervention approach in criminal justice, evaluation report of the pilot project]. Bundesamt für Justiz, Bern

2. Bartl G, Assailly JP, Chatenet F, Hatakka M, Keskinen E, Willmes-Lenz GE (2002) EU Project "Andrea", analysis of driver rehabilitation programmes. Kuratorium für Verkehrssicherheit, Vienna

3. Birnbaum D, Biehl B, Sage E, Scheffel B (2002) Evaluation des Nachschulungskurses "Mainz 77" [Evaluation of the driver improvement model "Mainz 77"]. Neue Zeitschrift für Verkehrsrecht 4:164-170

4. Birnbaum D, Biehl B, Seehars I (2005) Die Wirksamkeit des Nachschulungsmodells IRAK-S für erstmals alkoholauffällige Kraftfahrer [Effectiveness of the driver improvement model IRAK-S for DUI first offenders]. Zeitschrift für Verkehrssicherheit 51:20-207

5. Boets S, Escrihuela-Branz M, Klipp S (2009a) Belgium. In: Klipp S, Escrihuela-Branz M, Boets S, Meesmann U, Roesner S, Kraus L, Panosch E, Bukasa B, Braun E, Wenninger U, Siegrist S. Quality Management Systems established along with Driver Rehabilitation Schemes. DRUID Deliverable 5.2.3 (in press)

6. Boets S, Meesmann U, Klipp S, Bukasa B, Braun E, Panosch E, Wenninger U, Roesner S, Kraus L, Assailly JP (2009b) State of the art on driver rehabilitation: literature analysis \& provider survey. DRUID Deliverable 5.1.1 (in press)

7. Braun E, Bukasa B, Panosch E, Klipp S, Boets S, Meesmann U, Assailly JP, Rösner S, Wenninger U (2009) Provider Survey. In: Boets S, Meesmann U, Klipp S, Bukasa B, Braun E, Panosch E, Wenninger U, Roesner S, Kraus L, Assailly JP. State of the art on driver rehabilitation: literature analysis \& provider survey. DRUID Deliverable 5.1.1 (in press)

8. Bukasa B, Klipp S, Ponocny-Seliger E, Braun E, Panosch E, Boets S, Meesmann U, Assailly JP, Wenninger U (2009) Analyses of change process and components in driver rehabilitation courses. In: Bukasa B, Klipp S, Braun E, Panosch E, Wenninger U, Boets S, Meesmann U, Ponocny-Seliger E, Assailly JP. Good practice: in-depth analysis on recidivism reasons \& analysis of change process and components in driver rehabilitation courses. DRUID Deliverable 5.2.1 (in press)

9. Davies GP, Harland DG, Broughton J (1999) Drink/driver rehabilitation courses in England and Wales. TRL Research Report, 426, Crowthorne, Berkshire

10. Davies GP, Schmith LR (2003) Reconvictions of drink/drive course attenders: a six year follow up. TRL Report 574, Crowthorne, Berkshire

11. DiClemente CC, Carbonari JP, Addy RC, Velasquez MM (1996) Alternate short forms of a process of change scale for alcoholic treatment. International Congress on Behavioral Medicine, Washington

12. DiClemente CC, Hughes SO (1990) Stages of change profiles in outpatient alcoholism treatment. J Subst Abuse 2:217-235

13. DiClemente CC, McConnaughy EA, Norcross JC, Prochaska JO (1986) Integrative dimensions for psychotherapy. Int J Eclectic Psychother 5:256-274

14. DiClemente CC, Schlundt D, Gemmell L (2004) Readiness and stages of change in addiction treatment. Am J Addict 13:103-119

15. ETSC (2003) Cost effective EU transport safety measures. European Transport Safety Council, Brussels

16. Ferguson M, Sheehan M, Schonfeld C, Davey J (1998) Profiling drink driving offenders in Central Queensland-preliminary findings from the evaluation of a drink driving rehabilitation/ treatment program. Road Safety Research, Policing, Education Conference, Vol 1, Wellington, NZ

17. Festinger L (1995) A theory of cognitive dissonance. Stanford University Press, Stanford

18. Heather N, Gold R, Rollnick S (1991) Readiness to change questionnaire: user's manual. Technical report 15. National Drug and Alcohol Research Centre, University of New South Wales, Kensington, AUS

19. Jacobshagen W (1997) Nachschulungskurse für alkoholauffällige Fahranfänger (NAFA) - Kurspraxis, Wirksamkeit und Akzeptanz [Driver improvement courses for novice drivers DUI-practice, effectiveness and acceptance]. Verlag TÜV Rheinland, Cologne

20. Jacobshagen W (2001) Die Wirksamkeit des Modells BUSSBeratung, Untersuchung und Schulung-in der Sperrfrist bei alkoholauffälligen Kraftfahrern [The effectiveness of the BUSS model - advice, assessment and rehabilitation within the legal ban period-for DWI drivers]. Blutalkohol 38:233-249

21. Jacobshagen W, Nickel WR, Winkler W (1988) Wirksamkeit von Kursen für wiederholt alkoholauffällige Kraftfahrer [Effectiveness of courses for repeated DUI offenders]. Berichte der Bundesanstalt für Straßenwesen, Heft 64, Bergisch Gladbach

22. Klipp S (2008) Participant feedback study. Paper presented at International Expert Workshop on Driver Rehabilitation, Bergisch Gladbach

23. Klipp S, Braun E, Boets S, Bukasa B, Meesmann U, Panosch E, Assailly JP (2009) Review of existing DUI/DUID rehabilitation measures. In: Boets S, Meesmann U, Klipp S, Bukasa B, Braun E, Panosch E, Wenninger U, Roesner S, Kraus L, Assailly JP. State of the art on driver rehabilitation: literature analysis \& provider survey. DRUID Deliverable 5.1.1 (in press)

24. Klipp S, Bukasa B (2009) EU-Projekt DRUID: Erste ErgebnisseRehabilitation alkohol- und drogenauffälliger Fahrer [First results of the EU-project DRUID — rehabilitation of DUI and DUID offenders]. Z f Verkehrssicherheit 55:59-63

25. Klipp S, Glitsch E, Bornewasser M, Dünkel F (2005) Bestimmungsfaktoren der frühzeitigen Teilnahme alkoholauffälliger Kraftfahrer an Interventionsmaßnahmen [Determinants of early participation in drunk driving rehabilitation]. Blutalkohol 42:285302

26. Klipp S, Glitsch E, Bornewasser M, Dünkel F (2007) From precontemplation to action-an outcome evaluation of early interventions for DUI offenders. Proceedings of the 18th International Conference of Alcohol, Drugs and Traffic SafetyT2007, Seattle, WA

27. Marlatt GA, Donovan DM (2005) Relapse prevention: maintenance strategies in the treatment of addictive behaviors, 2nd edn. Guilford, New York

28. McConnaughy EA, Prochaska JO, Velicier WF (1983) Stages of change in psychotherapy: measurement and sample profiles. Psychother Theor Res Pract 20:368-375

29. Michalke H, Barklik-Chory C, Brandstätter C (1987) Driver Improvement. Effizienzkontrolle von Gruppentrainingsmaßnahmen für alkoholauffällige Kraftfahrer [Driver improvement. An evaluation of group-trainings for alcohol offenders in traffic]. Kuratorium für Verkehrssicherheit, Vienna

30. Miller WR, Tonigan JS (1996) Assessing drinker's motivation for change: the stages of change readiness and treatment eagerness scale (Socrates). Psychol Addict Behav 10:81-89

31. Polacsek M, Rogers EM, Woodall WG, Delaney H, Wheeler D, Rao N (2001) MADD victim impact panels and stages-of-change in drunk-driving prevention. J Studies Alcohol 62:344-350

32. Prochaska JO, DiClemente CC (1984) The transtheoretical approach: crossing traditional boundaries of therapy. Dow Jones Irwin, Homewood

33. Prochaska JO, DiClemente CC, Norcross J (1992) In search of how people change. Am Psychol 47:1102-1114 
34. Prochaska JO, Redding CA, Evers KE (1997) The transtheoretical model and stages of change. In: Glanz K, Lewis FM, Rimer BK (eds) Health behavior and health education: theory, research, and practice, 2nd edn. Jossey-Bass, San Francisco

35. Rider R, Kelley-Baker T, Voas RB, Murphy B, McKnight AJ, Levings $C$ (2006) The impact of a novel educational curriculum for first-time DUI offenders on intermediate outcomes relevant to DUI recidivism. Accid Anal Prev 38:482-489

36. Schützenhöfer A, Krainz D (1999) Auswirkungen von Driver Improvement-Maßnahmen auf die Legalbewährung [The effect of driver improvement measures on recidivism rates]. Z. f. Verkehrsrecht 4:138-143

37. Wells-Parker E, Kenne DR, Spratke KL, Williams MT (2000) Self-efficacy and motivation for controlling drinking and drinking/ driving: an investigation of changes across a driving under the influence (DUI) intervention program and of recidivism prediction. Addict Behav 25:229-238

38. Wells-Parker E, Williams M, Dill P, Kenne D (1998) Stages of change and self-efficacy for controlling drinking and driving: a psychometric analysis. Addict Behav 23:351-363

39. Wieczorek WF, Callahan CP, Morales MA (1997) Motivation for change among DWI offenders. In: Mercier-Guyon C (ed) Proceedings of the 14th International Conference of Alcohol, Drugs and Traffic-T'97, Annecy, France, pp 10691075

40. Winkler W (1974) Gruppengespräche nach wiederholter Trunkenheit am Steuer [Group talks after repeated DUI offenses]. Blutalkohol $11: 178-188$ 